Article

\title{
Changes in Stream Flow and Their Relationships with Climatic Variations and Anthropogenic Activities in the Poyang Lake Basin, China
}

\author{
Chaojun $\mathrm{Gu}^{1}$, Xingmin Mu ${ }^{1,2}$, Guangju Zhao ${ }^{1,2, *}$, Peng Gao ${ }^{1,2}$, Wenyi Sun ${ }^{1,2}$ and Qiang Yu ${ }^{1}$ \\ 1 State Key Laboratory of Soil Erosion and Dryland Farming on the Loess Plateau, Northwest A\&F University, \\ Xinong Road 26, Yangling 712100, China; chaojungu1990@163.com (C.G.); xmmu@ms.iswc.ac.cn (X.M.); \\ gaopeng@ms.iswc.ac.cn (P.G.); sunwy@ms.iswc.ac.cn (W.S.); yuq@igsnrr.ac.cn (Q.Y.) \\ 2 Institute of Soil and Water Conservation, Chinese Academy of Sciences \& Ministry of Water Resources, \\ Xinong Road 26, Yangling 712100, China \\ * Correspondence: gjzhao@ms.iswc.ac.cn; Tel.: +86-29-8701-2563; Fax: +86-29-8701-2411
}

Academic Editors: Sujay Kaushal, Paul Mayer and Arthur Gold

Received: 14 September 2016; Accepted: 25 November 2016; Published: 1 December 2016

\begin{abstract}
The Poyang Lake Basin has been suffering from severe water problems such as floods and droughts. This has led to great adverse impacts on local ecosystems and water resource utilization. It is therefore important to understand stream flow changes and their driving factors. In this paper, the dynamics of stream flow and precipitation in the Poyang Lake Basin between 1961 and 2012 were evaluated with the Mann-Kendall test, Theil-Sen approaches, Pettitt test, and Pearson's correlation. Stream flow was measured at the outlets of five major tributaries of Poyang Lake, while precipitation was recorded by fourteen meteorological stations located within the Poyang Lake Basin. Results showed that annual stream flow of all tributaries and the precipitation over the study area had insignificant $(P>0.1)$ temporal trends and change points, while significant trends and shifts were found in monthly scale. Stream flow concentration indices (SCI) at Waizhou, Meigang, and Wanjiabu stations showed significant $(P<0.05)$ decreasing trends with change points emerging in 1984 at Waizhou and 1978 at Wanjiabu, while there was no significant temporal trend and change point detected for the precipitation concentration indices (PCI). Correlation analysis indicated that area-average stream flow was closely related to area-average precipitation, but area-average SCI was insignificantly correlated with area-average PCI after change point (1984). El Niño/Southern Oscillation (ENSO) had greater impacts on stream flow than other climate indices, and La Niña events played a more important role in stream flow changes than EI Niño. Human activities, particularly in terms of reservoir constructions, largely altered the intra-annual distribution of stream flow but its effects on the amount of stream flow were relatively low. Results of this study provided a useful reference to regional water resource management and the prevention of flood and drought disasters.
\end{abstract}

Keywords: stream flow; climate change; reservoir; statistical test; the Poyang Lake Basin

\section{Introduction}

Poyang Lake, naturally connected to the Yangtze River, is the largest freshwater lake in China. The lake provides freshwater to approximately 10 million residents [1], and acts as one of the major agricultural production areas in China [2]. The lake receives stream flow from five tributaries, and exchanges water with the Yangtze River at Hukou (the junction of the Yangtze River and Poyang Lake) in the north. The influences of the water inflows from the tributaries and water exchange with the Yangtze River result in a considerable seasonal variation in the lake surface area [3]. The lake surface area can exceed $3000 \mathrm{~km}^{2}$ during wet season (March-August) while less than $1000 \mathrm{~km}^{2}$ during dry season (September-February) [4]. The significant fluctuations in the surface area of the lake form 
extensive wetlands with an area of about $2000 \mathrm{~km}^{2}$. The Poyang Lake wetland is famous for its abundant biodiversity and has been registered as internationally important habitats for many species of birds [5,6]. Poyang Lake also plays an important role in flood-mitigation storage and regulation of local climate $[7,8]$. In order to boost the economic development of the Poyang Lake Basin, the Chinese State Council officially approved "Poyang Lake Ecological Economic Zone Planning" in 2009 [9].

Hydrological regime is a fundamental hydrological component of Poyang Lake, and has significant impacts on the functioning of ecosystem and the economic prosperity [1,10]. Hydrological regimes of Poyang Lake have been largely altered since the 1990s [10]. The phenomenon mainly occurred in the form of severe floods in the 1990s and frequent drought after 2000. Three most severe floods during 1950-2000 occurred in the 1990s, i.e., 1998, 1996 and 1995 [11]. With the completion of the Three Rivers Gorges Dam (TGD) in the upper reaches of the Yangtze River (2003), the frequency of droughts of the Poyang Lake region increased. Four out of ten severe droughts during 1960-2010 occurred after 2003, i.e., 2004, 2005, 2008, and 2009 [10]. Economic losses induced by these floods and droughts were huge. For example, a flood in 1998 and a drought in 2003 respectively resulted in economic losses of more than 5.0 billion and 0.14 billion dollars [3,12]. The variations of basin stream flow, influence of TGD, and human activities within the Poyang Lake Basin were deemed to be the main driving forces of the above changes in hydrological regimes of the Poyang Lake Basin [13]. However, there are debates on which factor plays the dominant role in the hydrological regime change of the lake. Some researchers argued that the stream flow from its five tributaries was the primary source of major floods while the influences of the TGD only played a complimentary role $[7,10,13]$. Meanwhile, some scholars suggested that the influence of TGD was the primary causal factor for the alteration of the hydrology of the lake [3]. Other people showed that human activities, such as deforestation, large-scale land reclamation from lake were the primary cause for the shrinkage of surface area and volume of Poyang Lake between 1991-2000 and 2000-2010 [14,15].

Stream flow is an important residual outcome of the hydrologic cycle, in order to understand the hydrological regime change in the Poyang Lake Basin, the first step needed to figure out the stream flow variability within the basin. Previous studies have well examined the trends in stream flow and their driving factors at annual scales from the 1950s to 2005 [16]. However, stream flow changes were inconsistent among different months of a year due to the climate variability (e.g., changes in precipitation and evapotranspiration) and productive activities of humanity (e.g., irrigation, reservoir regulation) [17]. Annual stream flow changes would not well reflect the monthly stream flow changes if they did not follow the same pattern, and may mask some important changes in stream flow [18]. Therefore, previous studies may not investigate the stream flow change at a sufficient fine temporal scale, and a survey of monthly stream flow changes and their driving factors was necessary. Evaluations of monthly stream flow and the factors driving them would provide more detailed information than previous studies on the dynamics of water flow in the Poyang Lake Basin and the underlying mechanisms behind them. Meanwhile, studies on monthly stream flow changes would also be good for investigations into extreme events such as floods and droughts given they are often manifested seasonally. Moreover, other than the trend, the other variation characteristics such as the shifts in stream flow are seldom reported. Overall, there was a need to thoroughly investigate the monthly stream flow and its response to climate changes and anthropogenic disturbances.

Concentration of stream flow, which reflected the distribution pattern of the monthly stream flow throughout a year, also deserved an attention. Higher stream flow concentration represents greater percentages of the yearly total stream flow that occurs in a few months. Higher concentration of stream flow is expected to considerably impact water resources utilization, and also has the potential to cause floods and droughts [19]. There are many factors exerting impacts on stream flow concentration, such as precipitation, temperature, and evaporation [20]. Human activities, such as reservoir construction, deforestation, and soil and water conservation also have effects on intra-annual distribution of stream flow [21]. How would the intra-annual distribution of the Poyang Lake stream flow develop in the context of hydrological regime change? This is an urgent problem that needs to be resolved. 
As a consequence, the objectives of this study were: (a) to statistically analyze the spatiotemporal trends and shifts of monthly stream flow and precipitation; (b) to investigate the concentration of stream flow and precipitation; and (c) to explore the relationships between stream flow and its influencing factors.

\section{Data and Method}

\subsection{Study Area}

The Poyang Lake Basin covers an area of $1.6 \times 10^{5} \mathrm{~km}^{2}$, accounting for $9 \%$ of the Yangtze River Basin and nearly $97 \%$ of Jiangxi Province, China. The topography of the Poyang Lake Basin varies from highly mountainous regions in the west and east (maximum elevation of about $2147 \mathrm{~m}$ above sea-level) to alluvial plains in the central areas (minimum elevation of about $20 \mathrm{~m}$ below sea-level) (Figure 1). There are five tributaries Ganjiang River, Fuhe River, Xinjiang River, Raohe River and Xiushui River, discharged into the lake [22]. The basin is located in a subtropical wet climate zone with mean annual precipitation of $1622.1 \mathrm{~mm}$ (1961-2012), of which 55.9\% of the precipitation occurs in March to June and peaks in June (Figure 2a). Mean annual temperature is $17.8^{\circ} \mathrm{C}(1961-2012)$, and subject to a high seasonal variability. Temperature increases rapidly from January, peaks in July and then decreases (Figure 2b).

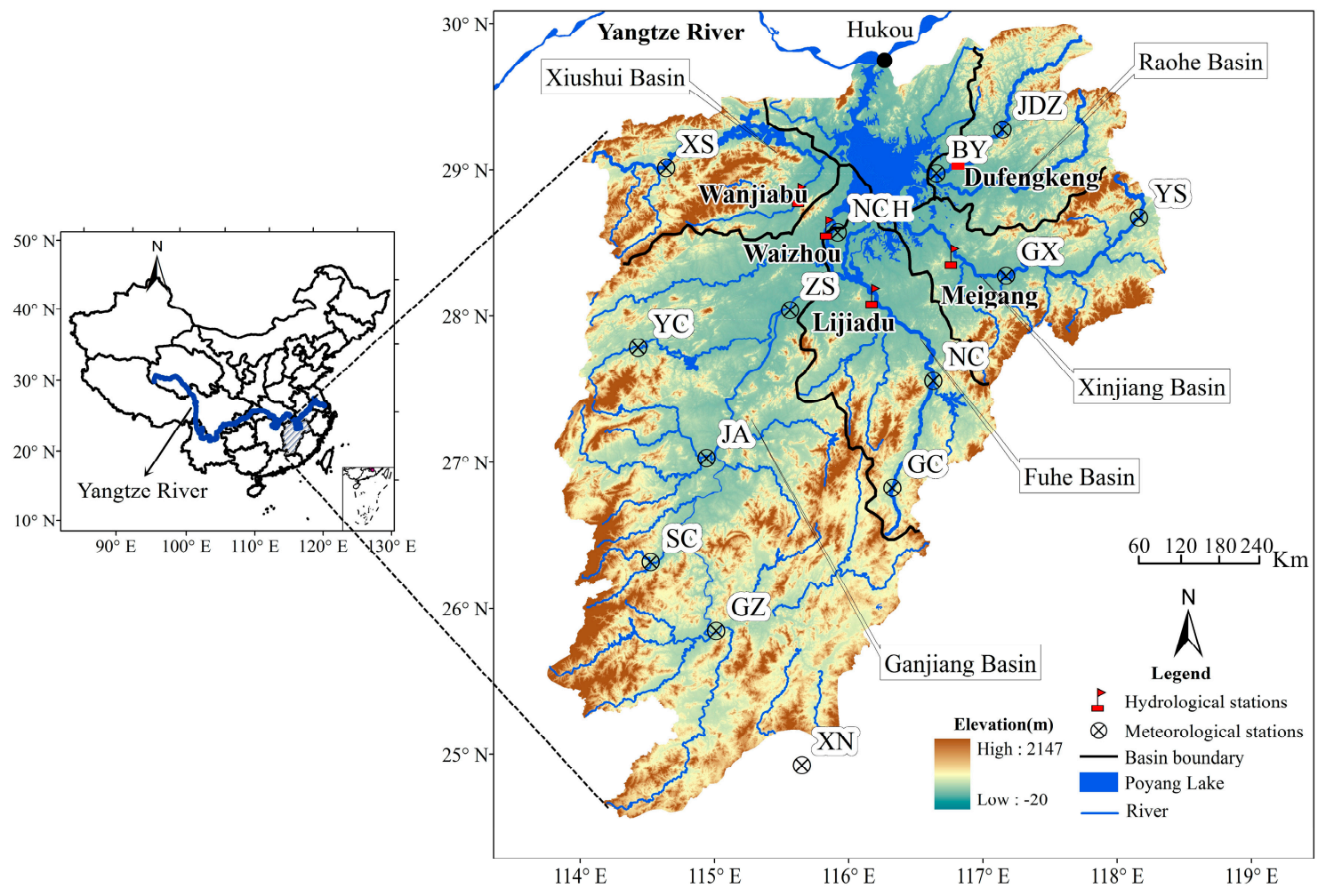

Figure 1. Location of the Poyang Lake Basin and the distribution of hydrological stations and meteorological stations (XS: Xiushui; JDZ: Jingdezhen; BY: Boyang; NCH: Nanchang; ZS: Zhangshu; YS: Yushan; GX: Guixi; NC: Nancheng; YC: Yichun; JA: Jian; GC: Guangchang; SC: Suichuan; GZ: Ganzhou; XN: Xunniao). 

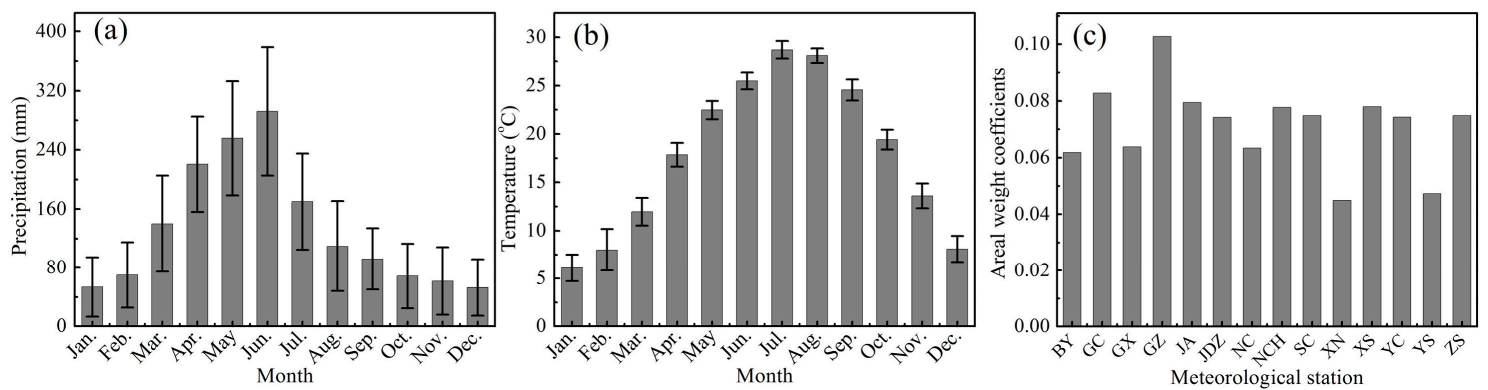

Figure 2. Mean monthly precipitation (a); and temperature (b); and the areal weight coefficients from Thiessen method for the 14 meteorological stations (c) in the Poyang Lake Basin from 1961 to 2012.

\subsection{Hydrological and Meteorological Data}

Hydrological data used in this study were the monthly stream flow measured at gauging stations located at the outlet of the five tributaries, i.e., Waizhou, Lijiadu, Meigang, Dufengkeng and Wanjiabu (Figure 1). They were provided by the Management Bureau of the Yangtze River (MBYR). Dufengkeng and Wanjiabu stations are located at the branches of Raohe River and Xiushui River. Waizhou, Lijiadu and Meigang stations are located at the lower reaches of Ganjiang River, Fuhe River and Xinjiang River (Figure 1). The control area of the five stations accounts for $74.5 \%$ of the total area of the Poyang Lake Basin (Table 1). The area-average stream flow (AAS) was defined as:

$$
\mathrm{AAS}=\sum_{i=1}^{5}\left(\mathrm{~S}_{i} \times \mathrm{A}_{i}\right) / \sum_{i=1}^{5} \mathrm{~A}_{i}
$$

where $S_{i}$ denotes the observed stream flow at each station; $A_{i}$ means the gauged area of each station; and $i$ represents the hydrological station (i.e., Waizhou, Lijiadu, Meigang, Dufengkeng, and Wanjiabu).

Table 1. Gauged area and the basin area percentage of the hydrological stations used in this study.

\begin{tabular}{ccccccc}
\hline Stations & Basins & Longitude (E) & Latitude (N) & $\begin{array}{c}\text { Gauged } \\
\text { Area }\left(\mathbf{k m}^{\mathbf{2}}\right)\end{array}$ & $\begin{array}{c}\text { Percentage of Total } \\
\text { Poyang Lake Basin (\%) }\end{array}$ & Year \\
\hline Waizhou & Ganjiang & $115^{\circ} 56^{\prime}$ & $28^{\circ} 38^{\prime}$ & 80,948 & 49.9 & $1961-2012$ \\
Lijiadu & Fuhe & $116^{\circ} 37^{\prime}$ & $28^{\circ} 46^{\prime}$ & 15,811 & 9.7 & $1961-2012$ \\
Meigang & Xinjiang & $116^{\circ} 48^{\prime}$ & $28^{\circ} 26^{\prime}$ & 15,535 & 9.6 & $1961-2012$ \\
Dufengkeng & Raohe & $117^{\circ} 12^{\prime}$ & $29^{\circ} 15^{\prime}$ & 5013 & 3.1 & $1961-2012$ \\
Wanjiabu & Xiushui & $115^{\circ} 37^{\prime}$ & $29^{\circ} 01^{\prime}$ & 3548 & 2.2 & $1961-2012$ \\
\hline
\end{tabular}

Meteorological data were provided by National Climate Centre of China Meteorological Administration (CMA) [23]. The data included daily precipitation between 1961 and 2012, and were obtained from 14 national weather stations inside the Poyang Lake Basin. The monthly data were derived from daily values. The quality of the dataset was checked by the CMA. We used an area weighting method to calculate the area-average precipitation of the whole Poyang Lake Basin. The areal weight coefficients for the 14 meteorological stations were calculated using the Thiessen Polygon, and shown in Figure 2c. In addition, the storage capacity of all large reservoirs in the Poyang Lake Basin since the 1960s was cited from Min et al. [24], and all the reservoirs operate normally at present [7].

\subsection{Method}

First, we used precipitation and stream flow concentration index to denote the intra-annual distribution of the monthly precipitation and stream flow in the Poyang Lake Basin. Then, non-parametric Mann-Kendall test [25,26] and Theil-Sen Approach (TSA) $[27,28]$ were employed to examine the temporal trends in stream flow and precipitation; non-parametric Pettitt test [29] 
was used to detect the change points of the hydro-climatic series. The change point is defined as the exact time when the mean of a time series before and after is significantly different. Finally, correlation/regression analysis was employed to explore the relationships between stream flow series and the influential factors.

\subsubsection{Concentration Index}

The precipitation concentration index (PCI) was originally proposed by Oliver [30] as an indicator of monthly precipitation heterogeneity. The PCI was calculated according to Equation (2),

$$
\mathrm{PCI}=\frac{\sum_{i=1}^{12} x_{i}{ }^{2}}{\left(\sum_{i=1}^{12} x_{i}\right)^{2}} \times 100
$$

where $x_{i}$ is the precipitation in $i$ month $(i=1,2, \ldots, 12)$.

A lower PCI indicates the greater uniformity of precipitation distribution. The lowest value of PCI is 8.3 in theory, representing the perfect uniformity. Oliver [30] suggested that PCI values of less than 10 represent a uniform precipitation distribution (i.e., low precipitation concentration); PCI values between 11 and 15 denote a moderate precipitation concentration; PCI values of 16 to 20 indicate irregular distribution (i.e., high precipitation concentration), and values greater than 20 represent a strong irregularity of precipitation distribution.

In this study, we also used the indicator to look at the intra-annual distribution of monthly stream flow, and defined it as stream flow concentration index (SCI).

\subsubsection{Mann-Kendall Test}

Mann-Kendall test (MK) is a rank-based non-parametric method that has been widely applied for examinations of trends in hydroclimatic series because it does not require the data to be normally distributed $[25,26]$. The calculation procedures of MK trend test are given as follows.

For a hydro-climatic time series $\left\{x_{1}, x_{2}, \ldots x_{n-1}, x_{n}\right\}$, the MK statistics $S$ can be calculated as,

$$
S=\sum_{i=1}^{n-1} \sum_{j=i+1}^{n} \operatorname{sgn}\left(x_{j}-x_{i}\right) \quad j>i
$$

The statistics $S$ obeys the normally distributed and the $\operatorname{sgn}()$ function was calculated as Equation (4). The sgn() function provides the rank and not the distribution of the observations.

$$
\operatorname{sgn}\left(x_{j}-x_{i}\right)\left\{\begin{array}{rll}
1 & \text { if } & x_{j}-x_{i}>0 \\
0 & \text { if } & x_{j}-x_{i}=0 \\
-1 & \text { if } & x_{j}-x_{i}<0
\end{array}\right.
$$

Then the standardized statistic $\mathrm{Z}$ is estimated as,

$$
Z=\left\{\begin{array}{cll}
\frac{s-1}{\operatorname{var}(s)} & \text { if } & s>0 \\
0 & \text { if } & s=0 \\
\frac{s+1}{\operatorname{var}(s)} & \text { if } & s<0
\end{array}\right.
$$

where the $\operatorname{var}(s)$ is described as,

$$
\operatorname{var}(s)=\frac{n(n-1)(2 n+5)}{18}
$$

The statistic $Z$ follows the standard normal distribution. If $|Z|>1.64$, the trend of a time series is significant at 0.1 significance levels. A positive (negative) value of $Z$ indicates an increasing 
(a decreasing) trend. The threshold values of $|\mathrm{Z}|$ at 0.05 and 0.01 significance levels are 1.96 and 2.58 , respectively. However, it is worth noting that the serial correlation of the time series will affect the ability of the MK test. It is necessary to remove the serial correlation before conducting the MK trend test. In this paper, trend-free pre-whitening (TFPW) approach was employed to remove the serial correlation [31].

The MK test can examine the trend of time series, but not the magnitude. Theil-Sen Approach was used to identify the magnitude of the trend in hydro-meteorological series. The magnitude of the trend was given by,

$$
\beta=\operatorname{Median}\left(\frac{x_{j}-x_{i}}{j-i}\right) \quad \forall i<j \quad 1<i<j<n
$$

where $\beta$ is Kendall slope, which indicates the change rate in one year; and $10 \beta$ denotes the change rate in a decade. From this method, the trend is evaluated quantitatively.

In order to detect the inter-annual variation in the hydro-climate variables $\left\{x_{1}, x_{2}, \ldots x_{n-1}, x_{n}\right\}$, sequential Mann-Kendall test was used. First, the statistics $d_{k}$ was calculated as,

$$
d_{k}=\sum_{i=1}^{k} r_{i} \quad(2 \leq k \leq n)
$$

where

$$
r_{i}=\left\{\begin{array}{cc}
+1 & x_{i}>x_{j} \\
0 & x_{i} \leq x_{j}
\end{array}\right.
$$

Equation (8) revealed that $d_{k}$ is the rank of $x_{k}$. Assuming that the series is random and independent, the statistic $d_{k}$ is distributed normally with the first moment of $\mathrm{E}\left[d_{k}\right]$ and the second moment of $\operatorname{Var}\left[d_{k}\right]$ respectively being as follows,

$$
\begin{gathered}
\mathrm{E}\left[d_{k}\right]=\frac{n(n-1)}{4} \\
\operatorname{Var}\left[d_{k}\right]=\frac{n(n-1)(2 n+5)}{72}
\end{gathered}
$$

Under the above assumption, the definition of the statistic index $\mathrm{UF}_{k}$ is calculated as,

$$
\mathrm{UF}_{k}=\frac{d_{k}-\mathrm{E}\left[d_{k}\right]}{\sqrt{\operatorname{Var}\left[d_{k}\right]}} \quad(k=1,2,3, \cdots, n)
$$

The change of $\mathrm{UF}_{k}$ reflects the variation in hydro-climate variables. $\mathrm{UF}_{k}>0(<0)$ represent the hydro-climate variables had an increasing (a decreasing) trend. If $\left|U_{k}\right|>1.64,1.96,2.58$, the change trend was significant at 0.1, 0.05 and 0.01, respectively. Then, using Equations (7)-(12) for the inverse series $\left(x_{n}, x_{n-1}, \ldots x_{2}, x_{1}\right)$, the statistic variables, $d_{k}, \mathrm{E}\left[d_{k}\right], \operatorname{Var}\left[d_{k}\right]$, and $\mathrm{UF}_{k}$, will be calculated for the inverse series. The value calculated with inverse series is termed $\mathrm{UB}_{k}$. If the exact intersection point of the two lines located within the critical limit line and the trend of the series is significant, the point is deemed as the possible change point [32].

\subsubsection{Pettitt Change Point Test}

Because sequential Mann-Kendall test cannot detect the accurate change point if there were multiple intersection points between $\mathrm{UF}_{k}$ and $\mathrm{UB}_{k}$ curves. Hence, we used Pettitt test to detect the change point in the hydro-climate series. The Pettitt test is a rank-based and non-parametric test to detect a significant change in the mean of a time series [33]. The test used Mann-Whitney statistic 
$U_{t, N}$ to verify whether two samples $x_{1}, x_{2} \ldots x_{t}$ and $x_{t+1}, \ldots x_{N}$ belong to the same population or not. Statistic $U_{t, N}$ is calculated as follows,

$$
U_{t, N}=U_{t-1, N}+\sum_{j=1}^{N} \operatorname{sgn}\left(x_{t}-x_{j}\right) \quad \text { in which } t=2,3, \cdots N
$$

where the function of $\operatorname{sgn}\left(x_{t}-x_{j}\right)$ is the same as Equation (4).

The number of times, for which a member of the first sample exceeds a member of the second sample, was counted in the test. The null hypothesis of Pettitt's test is no change point. Its statistic $K_{N}$ represented the most significant change point $t$ where the $\left|U_{t, N}\right|$ is maximum, and the associated probability $(P)$ used in the test was determined as,

$$
\begin{gathered}
K_{N}=\max _{1 \leq t \leq N}\left|U_{t, N}\right| \\
P \cong 2 \exp \left(-6\left(K_{N}\right)^{2} /\left(N^{3}+N^{2}\right)\right)
\end{gathered}
$$

When $P$ is smaller than the specific significance level, e.g., 0.1 in this study, the null hypothesis is rejected. The time $t$ when the $K_{N}$ occurs is the change point time.

\subsubsection{Atmospheric Circulation Index}

Pearson's correlation analysis between stream flow and eight atmospheric circulation indices were employed to determine the main atmospheric circulation types affecting the stream flow in the Poyang Lake Basin. The atmospheric circulation indices included Arctic Oscillation (AO), Pacific Decadal Oscillation (PDO), Northern Oscillation Index (NOI), North Atlantic Oscillation (NAO), Southern Oscillation Index (SOI), Pacific North American Index (PNA), Western Pacific Index (WP), and Oceanic Nino Index (ONI). They were downloaded from the National Oceanic and Atmospheric Administration [34] at monthly scales between 1961 and 2013. It is an open website, and it can be visited conveniently. The detailed description of the indices was available from the website, and the data quality was checked by the corresponding agencies before their release. These selected indices cover all of the potential factors affecting the climate in China $[35,36]$.

\section{Results}

\subsection{Change Detections for Stream Flow Time Series}

\subsubsection{Inter-Annual Variabilities of Stream Flow}

The average annual stream flow and stream flow concentration index (SCI) during 1961-2012 ranged from $2169.6 \mathrm{~m}^{3} / \mathrm{s}$ (Waizhou) to $110.3 \mathrm{~m}^{3} \cdot \mathrm{s}^{-1}$ (Wanjiabu), and from 12.9 (Waizhou) to 18.2 (Dufengkeng) (Table 2). The annual stream flow showed great variability during the study period. The amount of stream flow in 1998 was 6.2 times that in 1963 at Lijiadu station, being the largest difference between the maximum and minimum values. The coefficient of variation $\left(\mathrm{C}_{\mathrm{V}}\right)$ of stream flow and $\mathrm{SCI}$ at Waizhou was the smallest among the stations, showing the lowest inter-annual variability over the study period. The greatest $\mathrm{C}_{\mathrm{V}}$ of stream flow and $\mathrm{SCI}$ were found at Dufengkeng station, indicating that stream flow at this station has the highest inter-annual variability.

The inter-annual variability of stream flow was given by the MK approach (Figure 3a). For Waizhou station, stream flow showed a decreasing trend before 1969 (UF < 0), shifted to be stable during 1970-1990, and increased (UF > 0) after 1990. Stream flow at Lijiadu station increased during 1970-1985 and decreased during 2006-2012, while no obvious trend was found for other periods. Stream flow at Meigang, Dufengkeng, and Wanjiabu stations showed a similar inter-annual variability, i.e., an increasing trend throughout the whole study period. Moreover, the increasing trends were significant in mid-1970s and mid-1990s when UFs were all over critical limit, but the trends were 
feeble after 2005. No clear change point can be identified for the annual stream flow as the intersections between UF and UB were multiple and turbulent.

Table 2. Descriptive statistics of the annual stream flow at the five stations in the Poyang Lake Basin.

\begin{tabular}{ccccccccc}
\hline \multirow{2}{*}{ Station } & \multicolumn{5}{c}{ Stream Flow } \\
\cline { 2 - 9 } & $\mathbf{M a x}\left(\mathbf{m}^{\mathbf{3}} / \mathbf{s}\right)$ & $\mathbf{M i n}\left(\mathbf{m}^{\mathbf{3}} / \mathbf{s}\right)$ & Mean $\left(\mathbf{m}^{\mathbf{3}} / \mathbf{s}\right)$ & $\mathbf{C}_{\mathbf{V}}(\mathbf{\%})$ & Max & Min & Mean & $\mathbf{C}_{\mathbf{V}}(\mathbf{\%})$ \\
\hline Waizhou & $3642.8(1973)$ & $751.6(1963)$ & 2169.6 & 28.90 & $18.1(1977)$ & $10.1(1990)$ & 12.9 & 14.23 \\
Lijiadu & $718.3(1998)$ & $116.1(1963)$ & 391.7 & 38.25 & $24.6(1977)$ & $10.3(1990)$ & 16.5 & 19.09 \\
Meigang & $1091.8(1998)$ & $253.5(1963)$ & 574.5 & 33.61 & $26.8(1967)$ & $10.8(2001)$ & 15.3 & 20.00 \\
Dufengkeng & $304.2(1998)$ & $57.7(1963)$ & 143.8 & 38.45 & $31.1(1971)$ & $11.7(1972)$ & 18.2 & 23.61 \\
Wanjiabu & $227.8(1998)$ & $56.0(1968)$ & 110.3 & 32.02 & $19.9(1967)$ & $9.8(2001)$ & 13.6 & 17.56 \\
\hline
\end{tabular}

(a) Stream flow

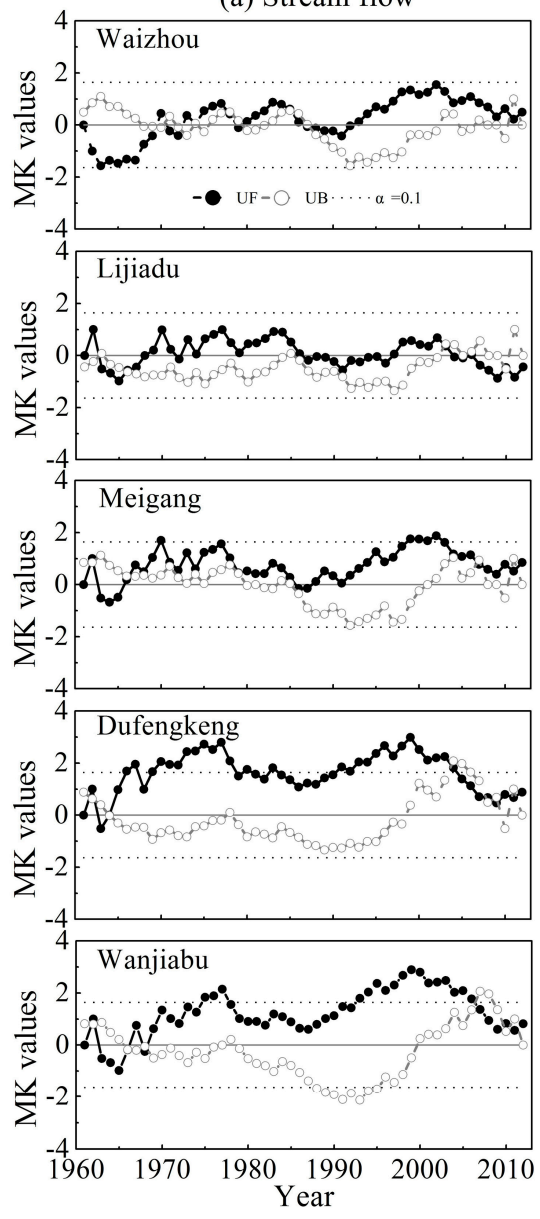

(b) SCI
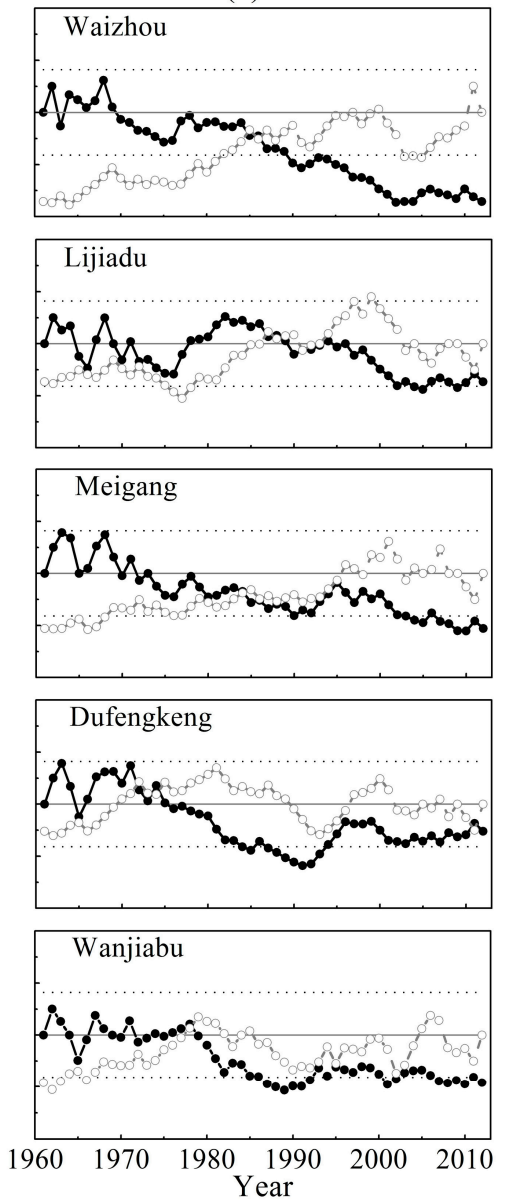

Figure 3. MK values of the: annual stream flow (a); and SCI (b) for the Poyang Lake Basin from 1961 to 2012.

With regard to the inter-annual variability of SCI (Figure 3b), SCI was in a decreasing trend after 1970 at Waizhou station and the trend reached 0.1 significance levels after 1990. Changes of SCI at Lijiadu station experienced an undulate stage (1961-1969), an increased stage (1978-1990), and two decreased stages (1969-1977 and 1990-2012). Change patterns of SCI at Meigang and Dufengkeng stations were similar, which can be divided into two stages (i.e., an increased stage before 1970s and a decreased stage thereafter). At Wanjiabu station, SCI fluctuated before 1979 but decreased sharply afterwards. The decreasing trend was significant after 1986. Specific intersections of UF and UB were 
found in 1984 for Waizhou station, and 1978 for Wanjiabu station, implying that the years might be the change points.

\subsubsection{Trends and Change Points of Stream Flow}

MK trend test showed that the long-term trend of annual stream flow for each station was not statistically significant at the level of 0.1 , with the Kendall slope ranging from $-8.29 \mathrm{~m}^{3} \cdot \mathrm{s}^{-1}$. decade $\mathrm{e}^{-1}$ (Lijiadu) to $37.16 \mathrm{~m}^{3} \cdot \mathrm{s}^{-1} \cdot$ decade $^{-1}$ (Waizhou) (Table 3). No change point was detected for annual stream flow at all the stations.

Table 3. Results of MK test, Theil-Sen approach and Pettitt test for stream flow time series in the Poyang Lake Basin from 1961 to 2012.

\begin{tabular}{|c|c|c|c|c|c|c|c|c|c|c|}
\hline \multirow[b]{2}{*}{ Time Series } & \multicolumn{2}{|c|}{ Waizhou } & \multicolumn{2}{|c|}{ Lijiadu } & \multicolumn{2}{|c|}{ Meigang } & \multicolumn{2}{|c|}{ Dufengkeng } & \multicolumn{2}{|c|}{ Wanjiabu } \\
\hline & $\mathbf{Z}$ & $\beta$ & $\mathrm{Z}$ & $\beta$ & $\mathrm{Z}$ & $\beta$ & $\mathrm{Z}$ & $\beta$ & $\mathrm{Z}$ & $\beta$ \\
\hline Annual & 0.50 & 3.716 & -0.43 & -0.829 & 0.86 & 1.634 & 0.89 & 0.450 & 0.83 & 0.272 \\
\hline January & 1.49 & 0.439 & 0.22 & 0.011 & $1.97^{* *}$ & $0.157^{* *}$ & $2.19^{* *}$ & $0.026^{* *}$ & $2.03^{* *}$ & $0.023^{* *}$ \\
\hline Change point & & & & & $1987^{* *}$ & & $1988^{* *}$ & & $1987 * *$ & \\
\hline February & 0.65 & 0.312 & -0.20 & -0.023 & 0.31 & 0.062 & 0.78 & 0.021 & 0.58 & 0.013 \\
\hline March & 1.14 & 0.838 & 0.58 & 0.109 & 1.35 & 0.318 & 1.02 & 0.021 & 0.99 & 0.037 \\
\hline April & -0.63 & -0.543 & -1.33 & -0.367 & 0.13 & 0.024 & -0.69 & -0.078 & -0.02 & -0.001 \\
\hline May & -0.69 & -0.661 & -1.21 & -0.426 & -0.99 & -0.394 & -0.24 & -0.028 & -0.61 & -0.057 \\
\hline June & -0.33 & -0.658 & -0.45 & -0.216 & 0.43 & 0.276 & 0.37 & 0.060 & -0.63 & -0.058 \\
\hline July & 0.37 & 0.484 & -0.05 & -0.008 & 0.43 & 0.105 & 1.50 & 0.157 & -0.10 & -0.012 \\
\hline August & $1.99^{* *}$ & $1.160 * *$ & 1.57 & 0.136 & $3.24^{* * *}$ & $0.402^{* * *}$ & $1.78^{*}$ & $0.069 *$ & $1.79 *$ & $0.061 *$ \\
\hline Change point & 1992 ** & & & & $1992 * * *$ & & $1988 *$ & & $1992 *$ & \\
\hline September & $2.62 * * *$ & $1.421^{* * *}$ & 1.38 & 0.108 & $1.89 *$ & $0.206^{*}$ & 0.92 & 0.020 & $2.18^{* *}$ & 0.070 ** \\
\hline Change point & $1978^{* *}$ & & & & 1986 * & & & & & \\
\hline October & 0.25 & 0.076 & -1.17 & -0.069 & 0.21 & 0.011 & 1.20 & 0.012 & 0.85 & 0.014 \\
\hline November & 0.67 & 0.175 & 0.17 & 0.014 & 1.60 & 0.107 & 1.44 & 0.015 & 1.29 & 0.021 \\
\hline December & 1.36 & 0.313 & 0.44 & 0.023 & $1.84^{*}$ & 0.102 * & 1.32 & 0.012 & 1.14 & 0.013 \\
\hline SCI & $-3.43^{* * *}$ & $-0.053^{* * *}$ & -1.48 & -0.029 & $-2.11^{* *}$ & $-0.049^{* *}$ & -1.03 & -0.034 & -1.84 * & -0.028 * \\
\hline Change point & $1984^{* * *}$ & & & & & & & & $1978 * *$ & \\
\hline
\end{tabular}

For monthly stream flow, significant increasing trends $(P<0.1)$ were found at Waizhou station (August, September), Meigang station (January, August, September, and December), Dufengkeng station (January and August), and Wanjiabu station (January, August, and September). The maximum and minimum of increasing rates were $14.2 \mathrm{~m}^{3} \cdot \mathrm{s}^{-1} \cdot$ decade $^{-1}$ in September at Waizhou station and $0.2 \mathrm{~m}^{3} \cdot \mathrm{s}^{-1} \cdot$ decade $^{-1}$ in January at Wanjiabu station. No significant trend $(P>0.1)$ was detected in monthly stream flow for Lijiadu station. Additionally, change points were found in the series of January, August, and September, and they mostly emerged between 1986 and 1992.

For SCI series, significant decreasing trends were observed at Waizhou, Meigang, and Wanjiabu stations (Table 3) with a Kendall trend of $-0.53,-0.49$, and -0.28 decade $^{-1}$, respectively. Change points were identified to be 1984 for SCI at Waizhou station and 1978 at Wanjiabu station (Figure 4a,d). The average value of SCI at Waizhou station shifted downward from 14.0 during 1961-1983 to 12.1 during 1984-2012 (Figure 4b). At Wanjiabu station, SCI shifted downward from 15.0 during 1961-1983 to 12.3 during 1984-2012 (Figure 4e). The amount of stream flow after the change point was lower than that before the change point in May and June (major flood period of the Poyang Lake Basin), which indicated that the stream flow became uniform after the change point (Figure $4 \mathrm{c}, \mathrm{f}$ ). 

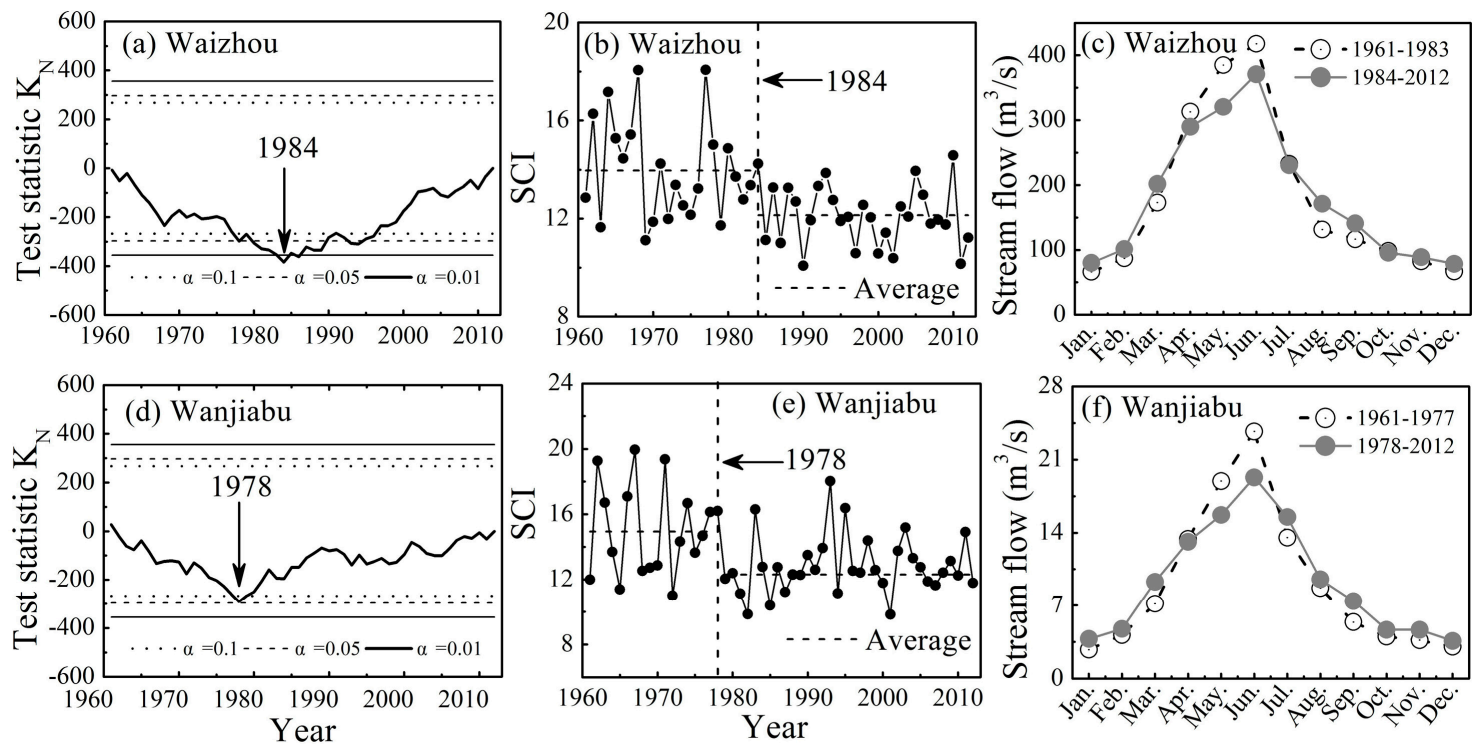

Figure 4. Pettitt test in SCI series at Waizhou station (a); change of average SCI before and after the change point at Waizhou station (b); intra-annual distribution of stream flow before and after the change point at Waizhou station (c); Pettitt test in SCI series at Wanjiabu station (d); change of average SCI before and after the change point at Wanjiabu station (e); intra-annual distribution of stream flow before and after the change point at Wanjiabu station (f).

\subsection{Change Detection for Precipitation}

\subsubsection{Annual Precipitation}

The long-term trend of area-average annual precipitation was insignificant, with a change rate of $15.6 \mathrm{~mm} \cdot$ decade $^{-1}$ (Figure 5a). Inter-annual variability of precipitation indicated that the 1990s was the wettest decade for the Poyang Lake Basin with an average value of $1765.7 \mathrm{~mm}$, which was $137.9 \mathrm{~mm}$ higher than the average value during 1961-2012. Spatially, annual precipitation was relatively higher in the northeastern part and relative lower precipitation in southwestern part of the study area (Figure 6a). For the 14 meteorological stations, positive but insignificant trends were observed in annual precipitation, and the change magnitude was generally higher in the central part than in other parts of the Poyang Lake Basin (Figure 6b). No change points were detected in annual precipitation series. The days of low precipitation $(\geq 0.1 \mathrm{~mm} /$ day) and high precipitation $(\geq 50 \mathrm{~mm} /$ day) were counted to investigate the extreme precipitation (Figure $5 c)$. No significant temporal trends $(P>0.1)$ were found for the days of low precipitation and high precipitation while days of high precipitation was more strongly correlated with annual precipitation (Figure 5d).

Annual PCI for the whole study area showed no significant temporal trends, with an average value of 13.3 from 1961 to 2012 (Figure 5b). The result indicates seasonal precipitation patterns. The distribution pattern of PCI was more complex than that of precipitation. PCI was relatively low in western and eastern parts and high in the central part of the Poyang Lake Basin (Figure 6c). There was also no significant trend and change point detected in the series of the PCI (Figure 6d). 

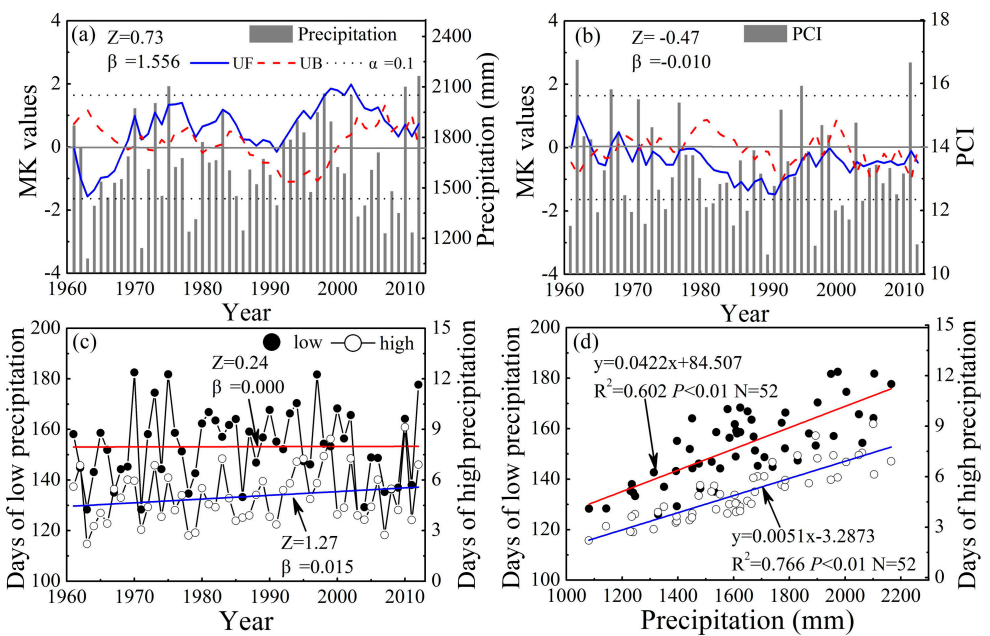

Figure 5. Area-average precipitation (a); area-average PCI (b); and the rainy and rainstorm day (c); and their correlation with precipitation (d) for the entire Poyang Lake Basin from 1961 to 2012.
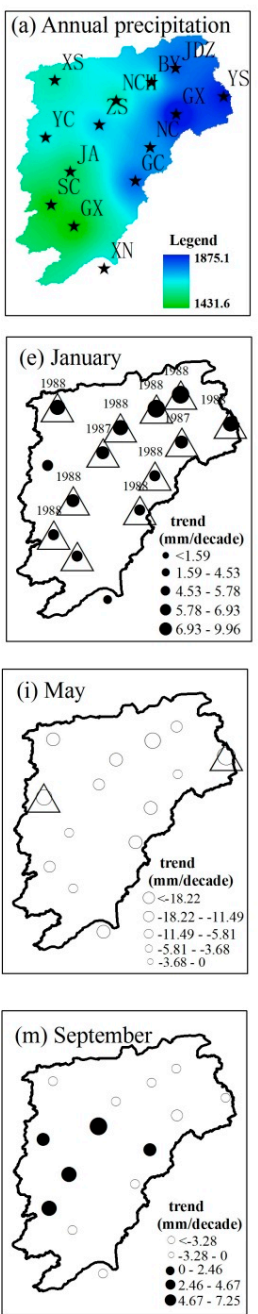
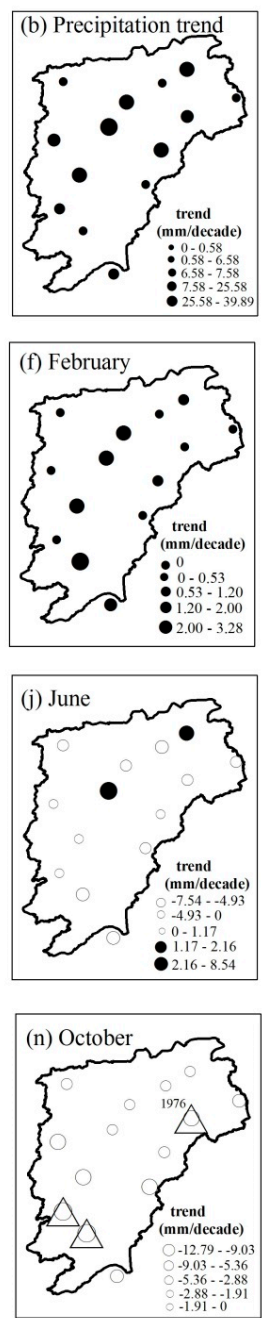
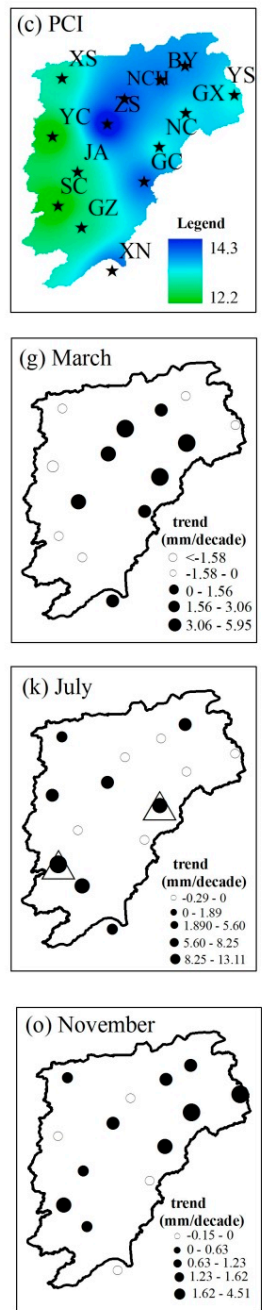
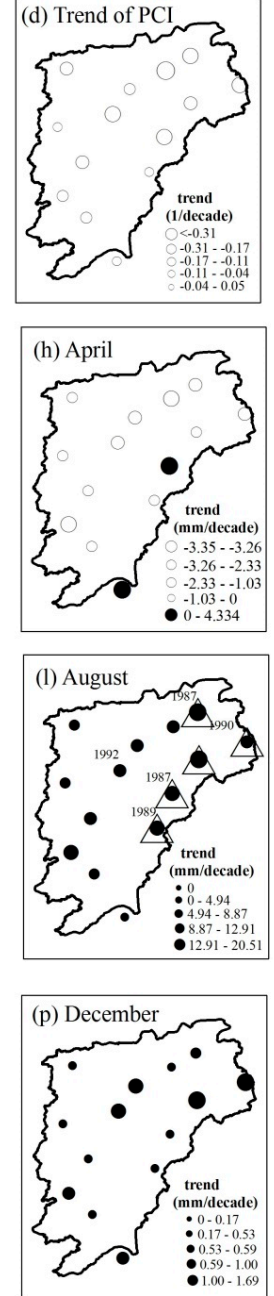

Figure 6. Distribution of annual precipitation (a); the trend of annual precipitation (b); distribution of PCI (c); trend of PCI (d); and trend of monthly precipitation (e-p) (filled circle denotes increasing trend, un-filled circle denotes decreasing trend, circle with triangle denotes the trend was significant at $P \leq 0.1)$. 


\subsubsection{Monthly Precipitation}

The spatial distribution of change trends in monthly precipitation is shown in Figure 6e-p. Significant positive trends in monthly precipitation mainly occurred in January, July, and August. For January, twelve out of fourteen $(85.7 \%)$ stations showed significant increasing trends and the change magnitude was relatively higher in northern compared to southern part of the Poyang Lake Basin (Figure 6e). Significant increasing trends for July were only found at Suichuang and Nancheng stations, with an increasing rate of 13.1 and $8.3 \mathrm{~mm} \cdot$ decade $^{-1}$, respectively (Figure 6k). For August, stations with significant increasing trends were mainly located in the eastern part of the study area (Figure 61). Significant negative trends were found in May and October (Figure 6i,n). The stations with significant decreasing trends for May were Yichun and Yushan, and the decreasing rate was -11.5 and $-18.2 \mathrm{~mm} \cdot$ decade $^{-1}$, respectively. In October, Suichuan, Ganxian, and Guixi stations underwent a significant decreasing trend, with a change rate of $-12.8,-9.0$, and $-5.9 \mathrm{~mm} \cdot$ decade $^{-1}$, respectively. In terms of $Z$ values of $M K$ test and Kendall slope, positive $Z$ and $\beta$ values were dominant in winter (i.e., January, February, December), while negative values were observed in other seasons, indicating winter of Poyang Lake Basin had a wetting tendency. Change points for monthly precipitation were detected in January, August and October. Moreover, all the abrupt changes emerged during 1987-1992 except for Guixi station in October (Figure 6n).

\subsection{Relationships between Stream Flow and Precipitation}

Area-average stream flow in the Poyang Lake Basin showed no significant temporal trends and change points with a change rate of $22.2 \mathrm{~m}^{3} \cdot \mathrm{s}^{-1} \cdot$ decade $^{-1}$ (Figure 7a). However, area-average SCI followed a significant decreasing trend, with a rate of -0.51 decade $^{-1}$. Moreover, a significant downward shift was detected in 1984 by both the Pettitt and MK test (Figure 7b).
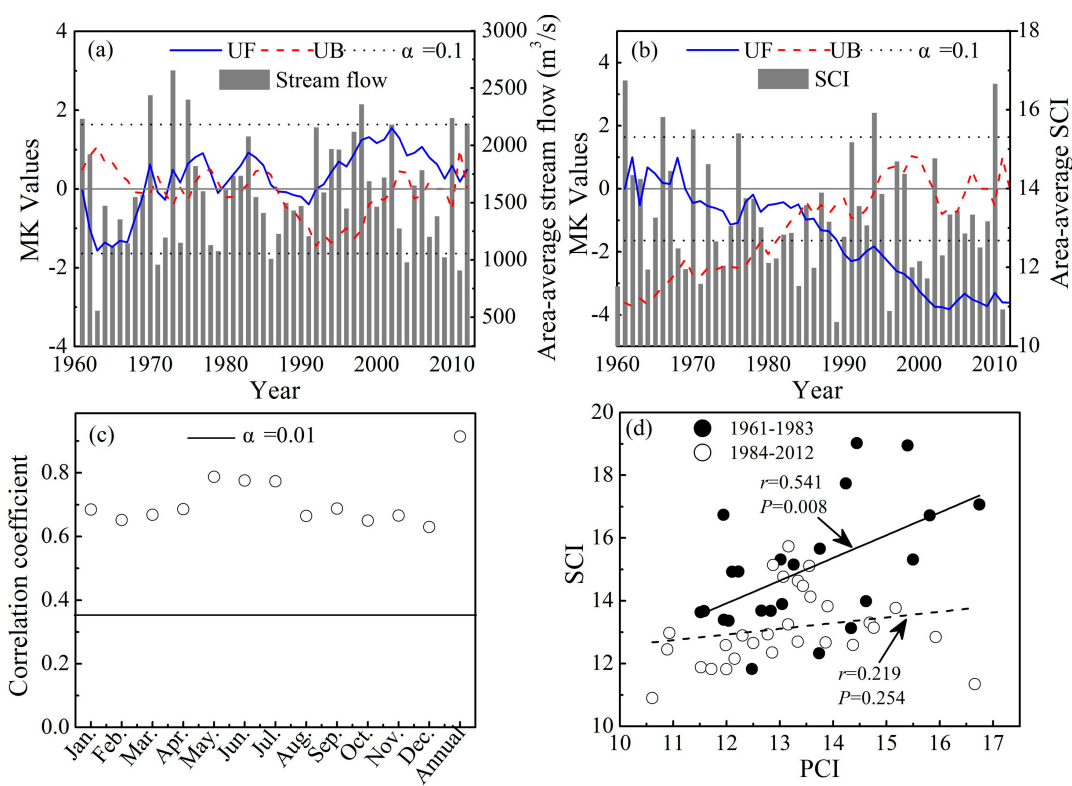

Figure 7. Area-average stream flow (a); area-average SCI series (b); Pearson's correlation coefficient between area-averaged stream flow and precipitation (c); and correlation coefficient between area-average SCI and PCI in different periods (d).

Annual and monthly area-average stream flow in the Poyang Lake Basin significantly correlated with precipitation (Figure 7c). The correlation coefficient $(r)$ between annual area-average stream flow and precipitation was 0.914 , and $r$ of monthly area-average stream flow and precipitation ranged from 0.629 in October to 0.788 in May, which were all significant at the 0.01 significance level. Area-average SCI showed a significant positive correlation with PCI from 1961 to $1984(r=0.541, P=0.008)$, 
and poorly correlated with PCI after $1984(r=0.219, P=0.254)$ (Figure $7 \mathrm{~d})$. This indicated that the intra-annual distribution of stream flow was different from the intra-annual distribution of precipitation after 1984.

\subsection{Linkage between Stream Flow and Climate Indices}

Stream flow was more closely related with Oceanic Nino Index (ONI) than others (i.e., AO, PDO, NOI, NAO, PNA, WP, and SOI) according to Pearson's correlation analysis (Figure 8). Significant positive correlation between precipitation and ONI was found in January, February, March, November, and December. ONI were used as El Niño/Southern Oscillation (ENSO) indicators, which were calculated as the three month running mean of NOAA ERSST.V4 SST anomalies in the Nino 3.4 region ( $5 \mathrm{~N}-5 \mathrm{~S}, 120-170 \mathrm{~W}$ ). Value of ONI continuously exceeding $0.5^{\circ} \mathrm{C}$ for five months can be defined as one EI Niño event, and ONI consecutively below $-0.5^{\circ} \mathrm{C}$ for five months corresponds to a La Niño even [37]. Hence, the study periods (1961-2012) were classified as EI Niño years, La Niño years, or normal years, as shown in Figure 9a. Annual stream flow in La Niño period were significantly $(P<0.05)$ greater than normal periods and EI Niño periods. The influences of El Niño and La Niña events on stream flow were different from month to month. EI Niño events generally resulted in stream flow decreases from January to September while the influences reversed during October-December. However, all the changes in stream flow during EI Niño periods were insignificant. La Niño events increased stream flow almost in all months, and stream flow in January, June, and October was increased significantly. This demonstrated that impacts of EI Niño events on stream flow changes were less substantial than La Niño events, which was confirmed by a regression analyses between monthly stream flow and El Niño/La Niño index (Figure 9b,c). Significant changes of stream flow between El Niño and La Niña events mainly occurred in January, February, June, and September.

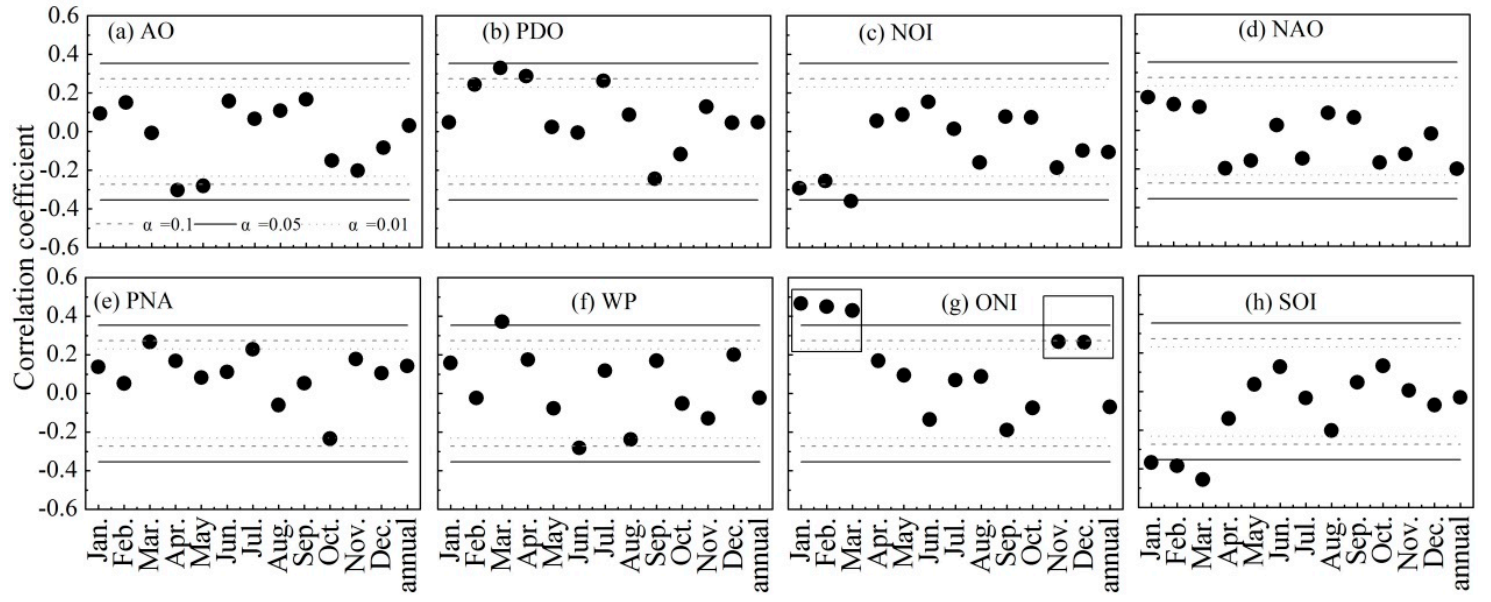

Figure 8. Pearson's correlations between stream flow and atmospheric circulation index (AO, Arctic Oscillation (a); PDO, Pacific Decadal Oscillation (b); NOI, Northern Oscillation Index (c); NAO, North Atlantic Oscillation (d); PNA, Pacific North American Index (e); WP, Western Pacific Index (f); ONI, Oceanic Nino Index (g); SOI, Southern Oscillation Index (h)).

Except for ONI, Pacific Decadal Oscillation (PDO) was most closely related to stream flow (Figure 8b). PDO was positively correlated with monthly stream flow in March $(r=0.244, P<0.1)$, April $(r=0.330, P<0.05)$, May $(r=0.287, P<0.05)$, July $(r=0.263, P<0.1)$, and September $(r=0.245$, $P<0.1$ ). Southern Oscillation Index (SOI) and Northern Oscillation Index (NOI) were significantly correlated with stream flow in January, February, and May. Significant correlations between AO, PNA, WP and stream flow were also found in certain months, while NAO was insignificantly related to stream flow in any of the months (Figure $8 \mathrm{a}, \mathrm{d}-\mathrm{f}$ ). 

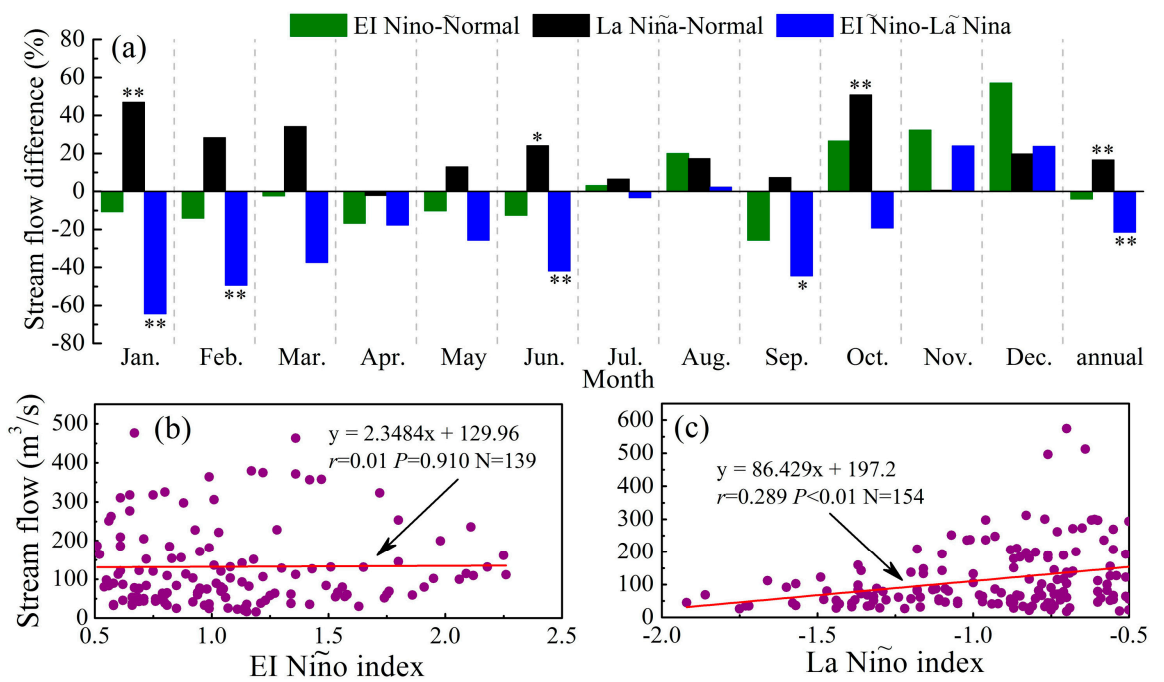

Figure 9. Monthly and annual stream flow changes in El Niño and La Niña year (a); and the relationships between monthly stream flow and ENSO events (EI Niño index and La Niño index) during 1961-2012 in the Poyang Lake Basin (b,c). The asterisks upon the bar indicate the statistical significance based on independent samples $t$ test (* significant at $P \leq 0.1$; ${ }^{* *}$ significant at $P \leq 0.05$ ).

\subsection{Relationship between Stream Flow and Reservoir Construction}

There were about 9530 reservoirs constructed with a total storage capacity of $300.2 \times 10^{8} \mathrm{~m}^{3}$ in the Poyang Lake Basin by 2012. Nine large- and medium-sized reservoirs constructed between 1961 and 2012 (Figure 10a). Reservoir storage capacity increased substantially during the period of 1960s-1970s and 2000s (Figure 10b). The total reservoir storage capacity in the 1980s was 2.5 times that of 1960s, and 3.3 times that of 1960s during 2006-2012. Although the reservoir storage capacity was influenced by the sediment deposition to some extent, the reservoir operated normally so far. Therefore, we considered that the effects of reservoir storage capacity on stream flow unchanged during 1961-2012. Based on this, no significant relationship was found between stream flow and storage capacity $(r=0.083$, $P=0.561)$. However, a significant negative correlation was found between SCI and total reservoir storage with a Pearson's correlation coefficient of $-0.473(P<0.01)$ (Figure 10c). SCI decreased dramatically as the reservoir storage capacity increased, particularly during the 1970s-1980s.

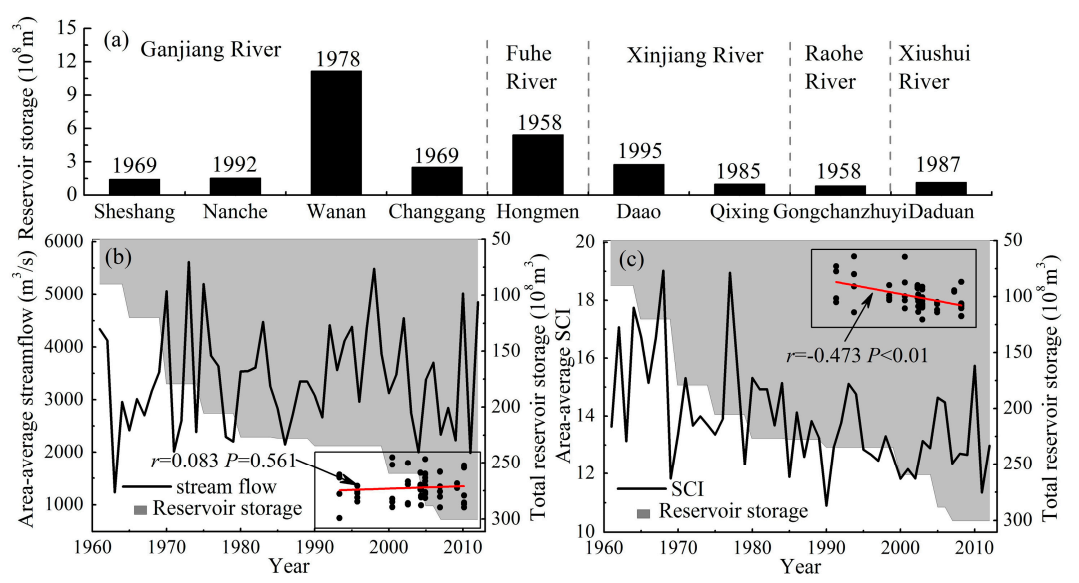

Figure 10. Large- and medium-sized reservoirs built during 1961-2012 in the five tributaries of the Poyang Lake Basin (a); total reservoir storage and area-average stream flow series (b); and total reservoir storage and area-average SCI series (c) in the Poyang Lake Basin from 1961 to 2012. 


\section{Discussions}

\subsection{Impacts of Climate Change on Stream Flow Variations}

The significant positive correlation of precipitation (Figure 7c) with stream flow implies that stream flow rates in the Poyang Lake Basin are primarily influenced by local weather patterns. Moreover, most of the rainfall in the region was observed to be associated with days of high precipitation ( $\geq 50 \mathrm{~mm} /$ day) (Figure $5 \mathrm{~d}$ ), indicating that precipitation was mainly dominated by extreme precipitation. Thus, the significant increase and change points of stream flow in January, August, September, and December were attributed to the significant increase of precipitation in these months (Table 3, Figure 6). Other than precipitation, stream flow was also influenced by evaporation [16,38]. Many documents have reported that temperature in the Poyang Lake Basin increased significantly over the past 50 years, especially after 1996 [39,40] (Figure 11). The warmer climate might accelerate evaporation from water surface, soil, shallow groundwater, and water stored in vegetation etc. and thus aggravated the loss of stream flow [41]. Sun et al. [42] found that pan evaporation in the Poyang Lake Basin increased from 2002, and it would attribute to the temperature increases. This was different from the snowmelt-dominated basins in China, such as Tarim River, western China [43] and Yarlung Zangbo River on the Tibetan Plateau [44], where elevated temperature produced higher stream flow because of enhanced snowmelt. However, as a whole, stream flow was more sensitive to precipitation than evaporation in the Poyang Lake Basin [45].
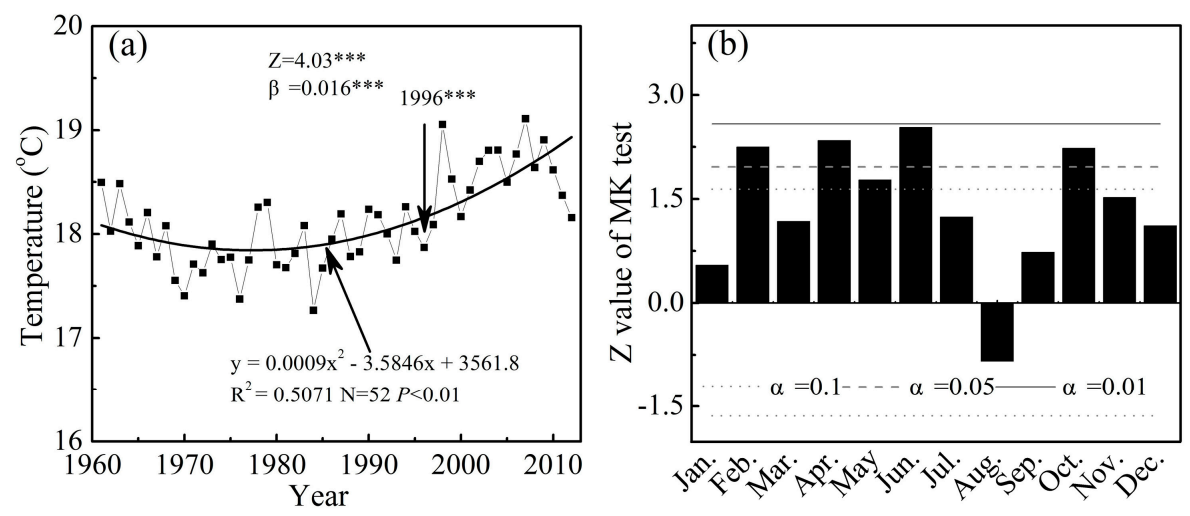

Figure 11. Temperature change (a); and the trend of monthly temperature (b) in the Poyang Lake Basin from 1961 to 2012 (*** significant at $P \leq 0.01$ ).

ENSO is a main mode of ocean-atmosphere system in the tropical Pacific region that significantly influences the climate in China [46]. East Asian winter and summer monsoons might be weak in El Niño periods while they can be enhanced in La Niño years [46]. Therefore, intensive rainfall events generally occurred in La Niño years and relative less precipitation appeared in El Niño periods. These might explain why stream flow increased in La Niño and decreased in El Niño years. Results of our study were consistent with the findings of Wei et al. [47], who found the impacts of La Niña events would induce increased stream flow in the Yangtze River Basin. Similar conclusions were also achieved by Ouyang et al. [48], and Chen et al. [49]. In addition to ONI, PDO was shown to have the greatest impact on stream flow (Figure 8). Ouyang et al. [48] illustrated that stream flow and precipitation were relatively lower in the PDO warm phase and higher in the PDO cool phase in the Yangtze River Basin, and the effects of PDO on stream flow was less than ENSO, which is in accordance with our findings.

\subsection{Potential Anthropogenic Impacts on Stream Flow Changes}

Anthropogenic interventions have affected stream flow mainly through alterations of surface conditions such as land clearance, irrigation, logging activity, mining, industrial consumption and construction of reservoirs [38]. In the Poyang Lake Basin, human activities mainly include afforestation 
and deforestation, land reclamation, river regulation, agriculture intensification and extensive reservoir construction [50]. Forest coverage of Poyang Lake Basin varied intensively over the past 50 year. It has been reported that forest coverage of the basin was about $30 \%$ in the $1970 \mathrm{~s}$, and recovered to over $60 \%$ at the end of 1990 s due to the large-scale implementation of soil and water conservation measures since the 1980s in the upstream area of Ganjiang basin [51]. On the one hand, forest vegetation canopy intercepts rainfall and reduces the amount of rainfall transformed into stream flow. On the other hand, vegetation cover increases rainfall infiltration and transpiration, which further results in decreasing the surface stream flow [32]. Undoubtedly, the tremendous changes in forest coverage have an influence on total transpiration that affects the basin hydrologic budget and residual stream flow.

Construction of reservoirs is another representative anthropogenic activity in the Poyang Lake Basin. Stream flow rate was insignificantly correlated with reservoir storage capacity while significant negative correlation was found between SCI and reservoir storage capacity. The results indicated that construction of reservoir significantly influenced the intra-annual distribution of stream flow. The majority of reservoirs (other than Wan'an reservoir in Ganjiang River) were mainly for agricultural irrigation [2], and the regulation modes of the reservoirs were distinctly seasonal [52]. The adjustment of the reservoir in stream flow in main-flood seasons (May, June, and July) is very weak due to the restriction of reservoir storage, making the correlation coefficients between stream flow and precipitation in these months higher than that for other months (Figure 7c). SCI was in a significant decreasing trend with a downward shift in 1984 (1978 at Wanjiabu) over the study period while PCI showed no significant trend and change point. Moreover, the change points of monthly precipitation occurred before that of SCI. The results indicated that precipitation alone was insufficient to explain the intra-annual distribution of stream flow. Consequently, the decreases in SCI could be attributed to the reservoir construction and operation activities. In addition, human water consumption is a likely cause of decreases in stream flow rates. However, Ye et al. [53] suggested that total water consumption of agricultural and industrial production accounted for $9 \%$ of the total stream flow in the Jiangxi Province from 1999 to 2004 . Overall, anthropogenic effects on the stream flow of the Poyang Lake Basin were limited.

\subsection{The Effects of Monthly Stream Flow Change on the Droughts and Floods of the Poyang Lake}

Trend and shift in annual stream flow of the Poyang Lake Basin was insignificant, while significant trends and shifts were found in January, August and September for most stations (Table 3). This result demonstrates that monthly data are more useful than annual mean data in detecting hydrological regime changes [18]. For the Poyang Lake Basin, droughts frequently occur in spring (March-May) and autumn (October-December), and floods mostly happens in summer (June-September). Stream flow in spring and autumn months had insignificant trends and shifts except for Meigang station in October, which indicated that basin stream flow inflows could not cause the droughts of Poyang Lake. The months coincide with periods of water impoundment in the TGD and low water levels in the Yangtze River, resulting in increased discharge outflow from Poyang Lake towards the Yangtze River [7]. Periods of low water storage in the lake thereby attributed to the operation of TGD [3]. In summer, four stations showed significant increasing trend in August and September, and the upward shifts emerged around the 1990s. These periods are the flood season of the Yangtze River Basin when the water level of the river is high, blocking the outflow from Poyang Lake towards the Yangtze River [12]. The results indicated that stream flow of the Poyang Lake Basin increased significantly in August and September, which is deemed to cause the floods of the lake. However, the intra-annual distribution pattern of stream flow in the Poyang Lake Basin was significantly affected by the reservoir (Figure 10). Consequently, some operation modes of the reservoir could be adopted to mitigate the droughts and floods in Poyang Lake. For instance, the reservoir should be managed to impound water in winter and early spring to prevent water flow into the Yangtze River. On the contrary, more water should be released in summer especially in June and July to increase outflow from Poyang Lake towards the Yangtze River. Additionally, annual regulation reservoirs could be built in the Poyang 
Lake Basin to avoid uneven distribution of stream flow at inter-annual scales (e.g., the 1990s and the 2000s). The driving factors of the droughts and floods in Poyang Lake are complex. We only focus on the Poyang Lake Basin because of data limitation. This may lead to an insufficient description and explanation of the droughts and floods in Poyang Lake.

\section{Conclusions}

This paper examined the trends and shifts for the past 52-year period of stream flow, precipitation and their concentration index in the Poyang Lake Basin. The relationships between stream flow and its influencing factors were investigated. The results are as follows:

(1) Annual stream flow at the five stations showed no significant temporal trend and change point from 1961 to 2012. However, three stations (Meigang, Dufengkeng and Wanjiabu) in January, four stations (Waizhou, Meigang, Dufengkeng, and Wanjiabu) in August, three stations (Waizhou, Meigang, and Wanjiabu) in September, and one station (Meigang) in December, showed significant increasing trends in stream flow with change points mostly emerging between 1986 and 1992. Stream flow concentration index (SCI) at Waizhou, Meigang and Wanjiabu stations had significant decreasing trends with change point being in 1984 at Waizhou and in 1978 at Wanjiabu.

(2) There was no significant time trend and change point found in annual precipitation among the 14 stations, while a significant positive trend was observed in January, July, and August, and a significant negative trend was found in May and October. Precipitation concentration index (PCI) also showed no significant time trend and change point over the study period.

(3) Area-average annual stream flow and precipitation all had no significant temporal trend and change point, and significant positive correlation was detected between them at annual and monthly scales. Area-average SCI showed significant decreasing trends while the trend of area-average PCI was insignificant. Moreover, area-average SCI had a downward shift in 1984, and showed no significant correlation with area-average PCI thereafter.

(4) Atmospheric circulation indices, such as ONI, PDO, and SOI, were more closely related to stream flow and precipitation than others. Human activities, especially the construction of reservoirs, played a limited role in the change of stream flow amount but significantly affected the intra-annual distribution pattern of stream flow in the Poyang Lake Basin.

Acknowledgments: This work was supported by the Non-profit Industry Financial Program of Ministry of Water Resources, China (201501049), Science \& Technology Development Foundation of Northwest A\&F University (A289021104), Youth Innovation Promotion Association, Chinese Academy of Sciences (2011289).

Author Contributions: Chaojun Gu carried out data processing, data analysis and wrote the paper. Xingmin Mu designed the research framework. Guangju Zhao, Peng Gao, Wenyi Sun and Qiang Yu offered guidance to complete the work and made revisions to the manuscript.

Conflicts of Interest: The authors declare no conflict of interest.

\section{References}

1. Feng, L.; Hu, C.; Chen, X.; Cai, X.; Tian, L.; Gan, W. Assessment of inundation changes of Poyang Lake using MODIS observations between 2000 and 2010. Remote Sens. Environ. 2012, 121, 80-92. [CrossRef]

2. Zhang, Q.; Sun, P.; Chen, X.; Jiang, T. Hydrological extremes in the Poyang Lake Basin, China: Changing properties, causes and impacts. Hydrol. Process. 2011, 25, 3121-3130. [CrossRef]

3. Zhang, Q.; Ye, X.C.; Werner, A.D.; Li, Y.L.; Yao, J.; Li, X.H.; Xu, C.Y. An investigation of enhanced recessions in Poyang Lake: Comparison of Yangtze River and local catchment impacts. J. Hydrol. 2014, 517, 425-434. [CrossRef]

4. Feng, L.; Hu, C.; Chen, X.; Li, R. Satellite observations make it possible to estimate Poyang Lake's water budget. Environ. Res. Lett. 2011, 6, 044023. [CrossRef]

5. Kanai, Y.; Ueta, M.; Germogenov, N.; Nagendran, M.; Mita, N.; Higuchi, H. Migration routes and important resting areas of Siberian cranes (Grus leucogeranus) between northeastern Siberia and China as revealed by satellite tracking. Biol. Conserv. 2002, 106, 339-346. [CrossRef] 
6. Wu, G.; De Leeuw, J.; Skidmore, A.K.; Prins, H.H.; Best, E.P.; Liu, Y. Will the Three Gorges Dam affect the underwater light climate of Vallisneria spiralis L. and food habitat of Siberian crane in Poyang Lake? Hydrobiologia 2009, 623, 213-222. [CrossRef]

7. Gao, J.H.; Jia, J.; Kettner, A.J.; Xing, F.; Wang, Y.P.; Xu, X.N.; Yang, Y.; Zou, X.Q.; Gao, S.; Qi, S. Changes in water and sediment exchange between the Changjiang River and Poyang Lake under natural and anthropogenic conditions, China. Sci. Total Environ. 2014, 481, 542-553. [CrossRef] [PubMed]

8. Nakayama, T.; Shankman, D. Impact of the Three-Gorges Dam and water transfer project on Changjiang floods. Glob. Planet. Chang. 2013, 100, 38-50. [CrossRef]

9. Zhang, Q.; Liu, J.; Singh, V.P.; Gu, X.; Chen, X. Evaluation of impacts of climate change and human activities on streamflow in the Poyang Lake basin, China. Hydrol. Process. 2016, 30, 2562-2576. [CrossRef]

10. Guo, H.; Hu, Q.; Jiang, T. Annual and seasonal stream flow responses to climate and land-cover changes in the Poyang Lake basin, China. J. Hydrol. 2008, 355, 106-122. [CrossRef]

11. Jiang, T.; Shi, Y. Global warming and its consequences in Yangtze River floods and damages. Adv. Earth Sci. 2003, 18, 277-284.

12. Li, X.; Zhang, Q. Variation of floods characteristics and their responses to climate and human activities in Poyang Lake, China. Chin. Geogr. Sci. 2015, 25, 13-25. [CrossRef]

13. Hu, Q.; Feng, S.; Guo, H.; Chen, G.; Jiang, T. Interactions of the Yangtze River flow and hydrologic processes of the Poyang Lake, China. J. Hydrol. 2007, 347, 90-100. [CrossRef]

14. Feng, L.; Hu, C.; Chen, X.; Zhao, X. Dramatic inundation changes of China's two largest freshwater lakes linked to the Three Gorges Dam. Environ. Sci. Technol. 2013, 47, 9628-9634. [CrossRef] [PubMed]

15. Liu, Y.; Wu, G.; Zhao, X. Recent declines in China's largest freshwater lake: Trend or regime shift? Environ. Res. Lett. 2013, 8, 014010. [CrossRef]

16. Zhao, G.; Hörmann, G.; Fohrer, N.; Zhang, Z.; Zhai, J. Stream flow Trends and Climate Variability Impacts in Poyang Lake Basin, China. Water Resour. Manag. 2010, 24, 689-706. [CrossRef]

17. Abghari, H.; Tabari, H.; Talaee, P.H. River flow trends in the west of Iran during the past 40 years: Impact of precipitation variability. Glob. Planet. Chang. 2013, 101, 52-60. [CrossRef]

18. Lu, X.X.; Ashmore, P.; Wang, J.F. Seasonal water discharge and sediment load changes in the Upper Yangtze, China. Mt. Res. Dev. 2003, 23, 56-64. [CrossRef]

19. Huang, J.; Sun, S.; Zhang, J. Detection of trends in precipitation during 1960-2008 in Jiangxi Province, southeast China. Theor. Appl. Climatol. 2013, 114, 237-251. [CrossRef]

20. Zheng, H.; Zhang, L.; Liu, C.; Shao, Q.; Fukushima, Y. Changes in stream flow regime in headwater catchments of the Yellow River Basin since the 1950s. Hydrol. Process. 2007, 21, 886-893. [CrossRef]

21. Baldwin, C.K.; Lall, U. Seasonality of stream flow: The upper Mississippi River. Water Resour. Res. 1999, 35, 1143-1154. [CrossRef]

22. Zhang, Q.; Liu, Y.; Yang, G.; Zhang, Z. Precipitation and hydrological variations and related associations with large-scale circulation in the Poyang Lake basin, China. Hydrol. Process. 2011, 25, 740-751. [CrossRef]

23. National Climate Centre of China Meteorological Administration. Available online: http://cdc.cma.gov.cn (accessed on 4 February 2016).

24. Min, Q.; Shi, J.; Min, D. Characteristics of sediment into and out of Poyanghu Lake from 1956 to 2005. J. China Hydrol. 2011, 31, 54-58. (In Chinese)

25. Mann, H.B. Nonparametric tests against trend. Econometrica 1945, 13, 245-259. [CrossRef]

26. Kendall, M.G. Rank Correlation Methods; Griffin: London, UK, 1975.

27. Theil, H. A rank-invariant method of linear and polynomial regression analysis. In Henri Theil's Contributions to Economics and Econometrics; Springer: Berlin, Germany, 1992; pp. 345-381.

28. Sen, P.K. Estimates of the regression coefficient based on Kendall's Tau. J. Am. Stat. Assoc. 1968, 63, 1379-1389. [CrossRef]

29. Pettitt, A. A non-parametric approach to the change-point problem. Appl. Stat. 1979, 28, 126-135. [CrossRef]

30. Oliver, J.E. Monthly precipitation distribution: A comparative index. Prof. Geogr. 1980, 32, 300-309. [CrossRef]

31. Yue, S.; Wang, C. The Mann-Kendall test modified by effective sample size to detect trend in serially correlated hydrological series. Water Resour. Manag. 2004, 18, 201-218. [CrossRef] 
32. Bao, Z.; Zhang, J.; Wang, G.; Fu, G.; He, R.; Yan, X.; Jin, J.; Liu, Y.; Zhang, A. Attribution for decreasing streamflow of the Haihe River Basin, northern China: Climate variability or human activities? J. Hydrol. 2012, 460, 117-129. [CrossRef]

33. Gao, P.; Jiang, G.; Wei, Y.; Mu, X.; Wang, F.; Zhao, G.; Sun, W. Streamflow regimes of the Yanhe River under climate and land use change, Loess Plateau, China. Hydrol. Process. 2015, 29, 2402-2413. [CrossRef]

34. National Oceanic and Atmospheric Administration. Available online: http://www.esrl.noaa.gov/psd/ data/climateindices/list (accessed 26 February 2016).

35. Dong, B.; Sutton, R.T.; Highwood, E.J.; Wilcox, L.J. Preferred response of the East Asian summer monsoon to local and non-local anthropogenic sulphur dioxide emissions. Clim. Dyn. 2016, 46, 1733-1751. [CrossRef]

36. You, Q.; Kang, S.; Aguilar, E.; Pepin, N.; Flügel, W.A.; Yan, Y.; Xu, Y.; Zhang, Y.; Huang, J. Changes in daily climate extremes in China and their connection to the large scale atmospheric circulation during 1961-2003. Clim. Dyn. 2011, 36, 2399-2417. [CrossRef]

37. Trenberth, K.E. The definition of El Nino. Bull. Am. Meteorol. Soc. 1997, 78, 2771. [CrossRef]

38. Milly, P.C.; Dunne, K.A.; Vecchia, A.V. Global pattern of trends in streamflow and water availability in a changing climate. Nature 2005, 438, 347-350. [CrossRef] [PubMed]

39. Zhang, Q.; Xiao, M.; Singh, V.P.; Wang, Y. Spatiotemporal variations of temperature and precipitation extremes in the Poyang Lake Basin, China. Theor. Appl. Climatol. 2016, 124, 855-864. [CrossRef]

40. Tao, H.; Fraedrich, K.; Menz, C.; Zhai, J. Trends in extreme temperature indices in the Poyang Lake Basin, China. Stoch. Environ. Res. Risk Assess. 2014, 28, 1543-1553. [CrossRef]

41. He, B.; Miao, C.; Shi, W. Trend, abrupt change, and periodicity of stream flow in the mainstream of Yellow River. Environ. Monit. Assess. 2013, 185, 6187-6199. [CrossRef] [PubMed]

42. Sun, S.L.; Zhou, S.Q.; Song, J.; Shi, J.H.; Gu, R.Y.; Ma, F.M. Change in pan evaporation and its driving factors in Jiangxi Province. Trans. CSAE 2010, 26, 59-65. (In Chinese)

43. Xu, J.; Li, W.; Ji, M.; Lu, F.; Dong, S. A comprehensive approach to characterization of the nonlinearity of runoff in the headwaters of the Tarim River, western China. Hydrol. Process. 2010, 24, 136-146. [CrossRef]

44. Liu, Z.; Yao, Z.; Huang, H.; Wu, S.; Liu, G. Land use and climate changes and their impacts on runoff in the Yarlung Zangbo River Basin, China. Land Degrad. Dev. 2014, 25, 203-215. [CrossRef]

45. Guo, H.; Ying, B.; Wang, Y.; Jiang, T. Runoff coefficients change and the analysis of the relationships between the climate factors and runoff coefficients in the Poyang Lake Basin (China):1955-2002. J. Lake Sci. 2007, 2, 163-169. (In Chinese)

46. Shao, J.; Wang, J.; Lv, S.; Bing, J. Spatial and temporal variability of seasonal precipitation in Poyang Lake Basin and possible links with climate indices. Hydrol. Res. 2016, 47. [CrossRef]

47. Wei, W.; Chang, Y.; Dai, Z. Streamflow changes of the Changjiang (Yangtze) River in the recent 60 years: Impacts of the East Asian summer monsoon, ENSO, and human activities. Quat. Int. 2014, 336, 98-107. [CrossRef]

48. Ouyang, R.; Liu, W.; Fu, G.; Liu, C.; Hu, L.; Wang, H. Linkages between ENSO/PDO signals and precipitation, stream flow in China during the last 100 years. Hydrol. Earth Syst. Sci. 2014, 18, 3651-3661. [CrossRef]

49. Chen, W.; Wang, L.; Xue, Y.; Sun, S. Variabilities of the spring river runoff system in East China and their relations to precipitation and sea surface temperature. Int. J. Climatol. 2009, 29, 1381-1394. [CrossRef]

50. Ye, X.; Zhang, Q.; Liu, J.; Li, X.; Xu, C.Y. Distinguishing the relative impacts of climate change and human activities on variation of streamflow in the Poyang Lake catchment, China. J. Hydrol. 2013, 494, 83-95. [CrossRef]

51. Liu, J.; Zhang, Q.; Xu, C.; Zhang, Z. Research on runoff variation characteristics of Poyang Lake watershed in the past 50 years. Trop. Geogr. 2009, 29, 213-224. (In Chinese)

52. Wei, L.X.; Yu, H.; Wang, Z.Y.; Bao, W.J. Characteristics and genesis analysis of variation of Poyang Lake flow into Yangtze River. Yangtze River 2014, 23, 91-97. (In Chinese)

53. Ye, X.; Zhang, Q.; Liu, J.; Li, L.J.; Guo, H. Impacts of climate change and human activities on runoff of Poyang Lake Catchment. J. Glaciol. Geocryol. 2009, 31, 835-842. (In Chinese)

(C) 2016 by the authors; licensee MDPI, Basel, Switzerland. This article is an open access article distributed under the terms and conditions of the Creative Commons Attribution (CC-BY) license (http:/ / creativecommons.org/licenses/by/4.0/). 